\title{
Mobile Money System Design for Illiterate Users in Rural Ethiopia
}

Mesfin F. Woldmariam

Addis Ababa University

mesfin.fikre@aau.edu.et

Solomon Atnafu

Addis Ababa University

solomon.atnafu@aau.edu.et
Gheorghita Ghinea

Brunel University

george.ghinea@brunel.ac.uk

Tor-Morten Grønli

NITH

tmg@nith.no

\begin{abstract}
Current mobile money systems provide users with hierarchical user interface and represent money as a positive rational numbers of the form 1,3 , 4.87...N. However, research indicates that rural communities that cannot read and write have a challenge entering such numbers in to mobile money system. Navigating through hierarchical text menu is also difficult to illiterate individuals. The present study uses concepts like memory placeholders, dragging \& dropping; swiping, temporary holding space, and frequency counter and proposed a system that consists of three layers. The first layer denotes user interface and uses photos of currency notes, second layer is a placeholder memory that keep record of the frequency of currency bill, and the last layer keeps record of the total digital money in the system. We believe that the proposed system enables illiterate to identify currency notes while making payments and receiving payments, count digital money while making payments and or receiving payments during transaction.
\end{abstract}

Keywords: Color of money, mobile money systems, interface for Illiterate users, counting money

\section{Introduction}

Mobile money can be classified as mobile transfer, mobile payments, and mobile financial services (UNCTAD 2012). M-transfer refers to when money is transferred from one user to another, mainly with the absence of exchanging goods and services. For example when one send or transfer money to his wife. In this case, mobile money replaces methods of sending money through friends or banks. On the other hand $\mathrm{m}$ payments refer to when money is exchanged between two users that involves ex-

adfa, p. 1, 2011.

(C) Springer-Verlag Berlin Heidelberg 2011 
change of goods and services. Example, when customers pay bills to utility companies. Finally, m-financial services refer to when mobile money is linked to a bank account to provide the user with a whole range of transactions (savings, credits etc.) that they normally access at banks. This requires banks to integrate mobile money service with the normal banking system, so that mobile money users can withdraw and or deposit money without visiting agents. This makes possible to deposit cash directly into bank account, transfer money directly to another account. It also makes electronic based loan collection and disbursement possible. According to the GSM Association some 130 mobile money systems have been implemented since March 2012 and this number is increasing continuously ${ }^{1}$. Deploying and using each of the above types of mobile money requires different level of sophistication and complication.

Ethiopia is one of the fastest growing and second most populated African Counties. There is a huge gap between financial service provision and service demand from citizens. Financial institutions serve mainly the upper and middle class people residing in urban areas (Collins et al.; 2009), (Duncome and Boateng 2009), (Kristof 2010), (Rutherford 1999). Rural communities (whether they are poor or rich) and poor people in urban areas were marginalized by existing financial institutions' service delivery model. However, mobile technology has already proved mobile phones are the best solution to provide financial services to such marginalized poor and remotely living people. For example, in Kenya M-PESA, mobile phone based financial service enabled marginalized people get access to formal financial institutions. The success history of mobile money services in Kenya, Tanzania, South Africa, Brazil, India etc., attracted the attention of many telecommunication companies, development and aid NGOs like (DFID), World Bank's International Finance Corporation (IFC), Consultative Group to Assist the Poor (CGAP), Bill \& Melinda Gates Foundation, Innovation for Poverty Action (IPA), research centre like the Institute for Money, Technology, \& Financial Inclusion (IMTFI), Innovations for Poverty Action (IPA), and governments in hope of providing an alternative means to enable the rural community access financial services, irrespective of their being located remotely. But there are many challenges when we think of providing financial services to people who cannot read and write. Issues like interfaces are among the major challenges.

The state of mobile phone usage is relatively on a good status among rural Ethiopians. Even in villages without electricity, mobile phone ownership was surprisingly widespread. The primary use of mobile phones was to reduce money spent on transportation costs, to meet families in urban and other rural areas, and to get updated about market prices. They are quite aware of the utility of mobile phones and even non owners easily describe how they would make use of it if they had one. However, there is a problem of how to operate and use. Most of the old people generally need the assistance of others to make a phone call and even to answer an incoming call. Literacy wise, over $70 \%$ of the adult populations are functionally illiterate and unedu-

\footnotetext{
${ }^{1}$ http://unctad.org/en/Pages/newsdetails.aspx?OriginalVersionID=134\&Sitemap x0 020_Taxonomy $=$ Technology\%20and\%20Logistics, retrieved on 15, June 2012
} 
cated. One in every two adults cannot read or write and the situation is worse for adult women. Many of them have low or no level of textual literacy, and they have no prior exposure to computing technology.

In addition to the problem of illiteracy, there are many languages in the country, predominantly, Amharic, Oromigna, Tigrina, Somali, and Guaragigna that challenges digital communication. For example an Amharic speaker can communicate with Oromigna speaker through symbols like (color of money, showing fingers etc) or through some intermediaries that speak both languages. Color of money notes has dual purpose; as a means to identify among currency notes- by the illiterate individuals and as a means of communication language-when people speaking different language meet for transaction.

In addition to these, the physicality of money itself also enabled illiterate individuals to move money around and make simple mathematical computations (for example dividing 87 birr to 5 people), to sort money according to economic value. Thus it is interesting to examine how existence of many languages affects communication and transactions as we go from paper based money into digital money. Thus, it seems important to think the possibility of using photos of existing money color and denominations for interface design.

This paper is organized as follows: section two reviews the literature regarding interface design for mobile money systems, section three deals with problems of existing interfaces and mobile money representations, whilst section four presents money practices of illiterate users. Section five focuses on proposed mobile money system, while section six summarizes our work and highlights future work.

\section{Interface Design for Mobile Money Systems}

Literature like (Lehrer and West 2013) indicates literacy is the main challenge to bringing financial services to marginalized and poor people. Many of the information systems we talk about require some level of literacy and we have overlooked the experience and know-how of the poor with regards to how to use ICT systems. If one cannot read his/her name, cannot spell his identification number, cannot spell his phone number, cannot understand his/her receipt, it is simple to imagine the frustration he/she develop if transactions made digitally or if money goes digital. For example, a study in Bangladesh by (Ahmed, Zaber, and Guha 2013) found that the illiterate do not even remember their mobile phone number and have their number written on piece of paper for them. This makes the case to be even more challenging when it comes to the issue of mobile money.

Reviewing the literature for possible solutions to the illiteracy problem reveals the use of icons, verbal instructions, and photographs (Lehrer and West 2013). It is found that illiterate users that have no experience of using icons do not use them easily. The use of verbal instructions in interface design also revealed that users have some difficulties with making the translation from verbal instruction to manual action. Terms like "top, right" or "the square", "bottom" etc was confusing. This is the result of lack of previous exercise and practice with the use of such abstractions. They also experi- 
ment photograph for interface design and the result was quite impressive. Illiterate easily understand photos and there is no abstractions.

The study by Medhi et al. (2009) also revealed that illiterate users are comfortable with non-text designs over text-based designs. The use of images and or graph for user interface is also considered by researchers like Grisedale et al. (1997), Medhi et al. (2006) and Parikh et al. (2003). Research, such as that described in (Medhi et al 2006) and (Ruth 2013) also considered voice instructions and audio annotations as a powerful way to design user interface for the illiterates. Even though there are some authors (Parikh et al 2003) states the possibility of using numbers is acceptable, it appears this is not the case from the observation we made in the field.

Thus, it can be understood from the review of the literature, designing for illiterate people needs to consider principles like: (1) visual-illiterate people often do not learn to think in terms of abstractions, so signs, icons, and diagrams may not make sense to them, (2) illiterate people can be confused if what they see is different from what they know, (3) the use of audio based interfaces if recommended-as it avoids literacy related issues (Medhi et al., 2006) and (Ruth 2013, and (4) menu based interfaces are questionable for novice users (Jones et al 2000). Therefore, it appears important to explore the use of currency photos for interface design.

\section{Existing Mobile Money Interfaces and Money Representation}

Currently existing mobile money services use hierarchical menus, as indicated below and represent and store digital money as a positive rational numbers of the form 1,2, $3,4.25,0.43, \ldots, \mathrm{N}$ and enable users get access to their accounts through some security codes based on either SMS or USSD. From the illiterate users' perspective both menu based interface design and money representations have challenges. A simple observation (Fig. 1 below) of M-birr in Ethiopia and M-PESA in Kenya reveals the interface is menu-based where transactions are conducted by selecting options that appear on the mobile phone's display, organized as hierarchical menu options. Users use up-down keys to select between options on the menu. As stated by previous research detailed in the previous section, such a textual menu-based interface is not easy for illiterate individuals. One can imagine how difficult the following interface will be to illiterate people that cannot read and write even their name.

Unlike previous solutions that represent digital money in a positive rational number avoiding the issue of color and denomination, this paper assumes that mobile money services will take money notes as they appear in their paper format, digitizing money notes while maintaining color and denomination. This means for example, we will have digital money of 5 cents, 10 cents, 25 cents, 50 cents, 1 birr note, 5 birr note, 10 birr note, 50 birr note, and 100 birr notes. Each of this will form a stack and will appear on top of the mobile phone screen when users swipe on the different colored money interface. As stated by the research described in the previous section, such use of photos of money and their denomination can enable illiterate individuals to understand and use such a system easily. 


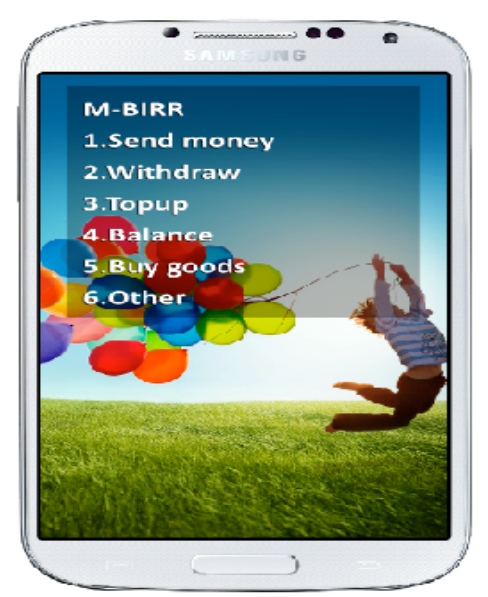

M-BIRR of Ethiopia



M-PESA of Kenya

Fig. 1. Interface of M-BIRR and M-PESA

\section{Money Practices of Rural Illiterate Individuals}

Field work undertaken in 2012 revealed that many old-aged women and men could not read in their own spoken language, and many of them could not read anything at all. Many of them do not understand symbols, icons, illustrations, and instructions. On the other hand, we contend that any system designed to serve them should work for them. Thus this brings a challenge to designers of the system to make sure such users can able to use their system. According to the field work, the majority of the study population identifies currency notes based on color, images, and sizes, and not based on values inscribed. This raises the question, how could illiterate individuals transact in an electronic payment ecosystem?

The physicality of money itself also enabled illiterate users to move money around and make simple mathematical computations (for example to divide 87 birr to 5 people), they lay say an amount of 10 birr into 5 places and keep on adding on to it until they exhaust the money to be shared. Individuals also arrange money from the smallest denominator to the largest $(1,5,10,50$, and 100) birr money notes. Such sorting makes money counting easy and fast. Calculating the total is also easy when it is sorted than not sorted, said a respondent. Fig. 2 shows how farmers sort money according to economic value from highest to the smallest denomination and identify based on color. 


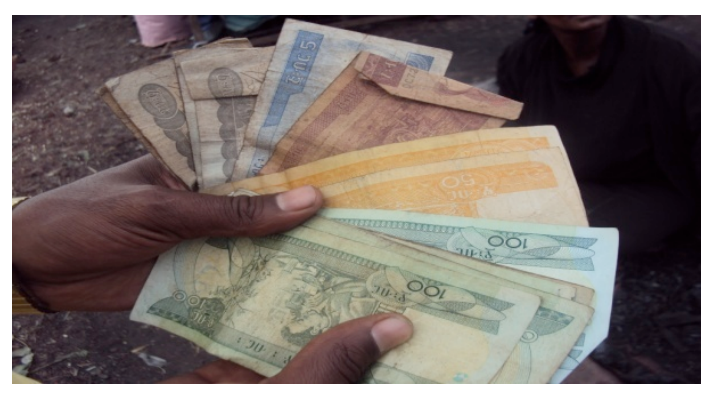

Fig. 2. Color based identification and sorting of money

In order to propose our mobile money system design for rural illiterate Ethiopians, it is important to look into the everyday practices of such communities. From the field work data of 2012, we found interesting practices that inform new system design and worth explanation: (1) practice of money counting while making payments and or receiving payments, to know balances at hand, (2) making money changes during transactions, (3) sorting and arranging money notes based on denomination, (4) making simple mathematical computation (addition, subtraction, division, and multiplication. Any new system to be designed for illiterates need to facilitate the execution of these practices in digital money form too. It is our belief that this paper has contributed towards many of these issues.

\subsection{Money counting practice}

Counting money bills is an important task during transaction even in normal circumstances. Be it during transactions or at other social and religious events, people do count money: while accepting payments, making payments, and making and accepting changes etc. As a matter of culture and practice, individuals count each time they receive cash payments and when they make payments, mainly during transactions. To do so, individuals sort every bill and arrange them from the biggest bill to the smallest one and count the bills. To count the money, they hold the stack of money in one hand and count with the other hand. Sometimes they count from both edges so that they can get around the situation when some bills are folded and counted as two bills. Fig. 3 below shows this practice.

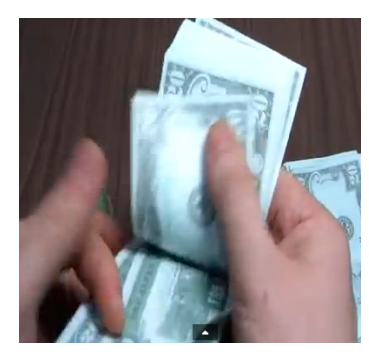

Fig. 3. Money counting practice 
The issue is, given that digital money is represented by a positive rational number, how do illiterate users count money? This is one of the questions this paper addresses.

\subsection{Changes during transaction}

If we assume digital money representation in the form of digitizing existing money bills by maintaining the color and denomination, the issue of changes during transaction and money transfer is important. For example, assume one has a digital money bill of 5 birr and wanted to pay 3 birr to a shoe polisher. In this case, similar to the paper money, one would give the shoe polisher 5 birr bill and expect him to give change to the value of 2 birr. Now the issue is how do we do this in digital money (mobile money)? One of the options is to design a mobile money system that can change a 5 birr bill into five ( 1 birr bills) so that a user can pay the three of them to the shoe polisher. In this case, the system will automatically update the frequency of 5 birr bill and 1 birr bills as well as the total value in the system. That is, it contains the idea of a system which splits bills automatically when needed!

\subsection{Sorting and arranging money based on denomination}

To count and keep money, individuals also arrange money bills according to their category. Again our proposed system introduces the memory placeholders' concept which enables to keep different money bills into different categories.

\subsection{Undertaking simple mathematics operations}

The physicality of the bills also has another advantage to illiterate users, namely that they can do simple maths by moving money around. For example, if they want to divide 65 birr among 6 individuals, they do it step by step. Firstly, they approximately allocate 9 birr to each of them and when they remain with some extra, they keep on giving one additional birr to each individuals and keep doing so until they share it equally. Thus, again the current proposed system will have a feature that enables individuals to do such maths.

\section{$5 \quad$ Proposed rural mobile money system design}

Based on the above everyday money practices of illiterate individuals, we propose to use photographs of each bill and coin in use in Ethiopia for the interface design of mobile money system. The bills and coins are similar (same color, images, and denominations) to paper money, except they appear digitally in the apparatus. Accordingly, keeping these metadata of the bills serve the illiterate users as a means of: (1) communication among people of different language, (2) counting and making mathematical computations and (3) identifying and differentiating among currency notes. To address the issue of counting money, making money changes by the system, performing simple maths, we introduced concepts like: dragging and dropping, memory 
placeholder, swiping, frequency counter, total controller, audio assist, and temporary holding place. The design of the system has three layers as indicated in Fig. 4 below.

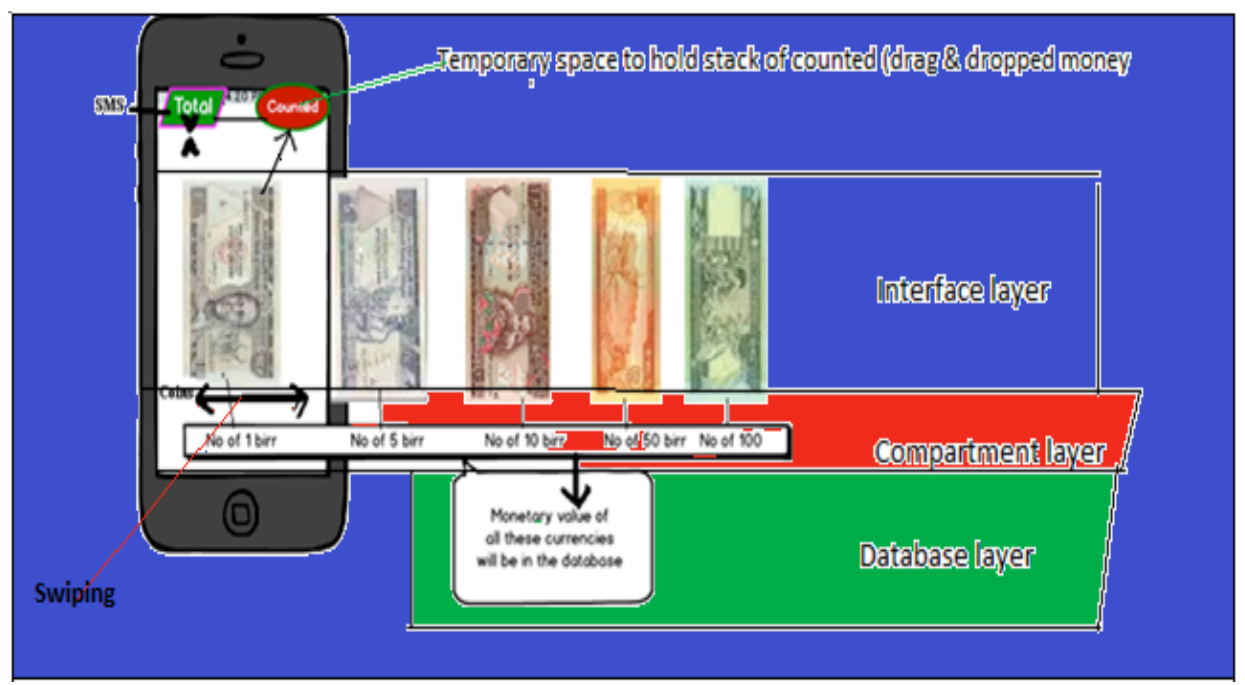

Fig. 4. Design of mobile money information system

We now describe the components that constitute the system.

\subsection{Interface layer}

This layer displays the different money bills and cents one after the other. When the user swipes to the left side, cents of 5, 10, 25, and 50 will appear visible on the screen. Swiping to the right side will make bills $(1,5,10,50$, and 100) to be visible on the screen one after the other. So, through swiping left and right, a user can get access to the cents or bills he/she would like to make use of.

\subsection{Compartment layer}

This layer consists of compartments (memory place holders) for every money bill/notes and cents. This means that, when say a bill of 10 birr is visible and is on screen, it means that the user is reading this memory space. The memory spaces count and keep record of the frequency or number of the bills. For example if a user has 3 bills of 50 birr notes and expends 2 of them, the system will update data in this compartment to 1 . The same logic is applicable for the other bills too.

\subsection{Database layer}

This layer shows the total of monetary value (sum of all currencies and cents in their respective compartments/memory place holder) that the user has. It displays the total 
amount of money in the phone at particular time. When money is expended or received, both the compartment and database layer will be updated automatically, to reflect current balance.

\subsection{Top two icons (red and green)}

As indicated in Fig. 4 above, our design also consists of other elements indicated by green and red colors. The placeholder marked by the red color is a space we place money to be paid. The user will count money by dragging and dropping through the interface layer from the compartment and places the counted money in this red color temporary holding place. The green one is an audio assisted icon that "speaks" the amount of money counted and placed to be paid or transferred.

\section{Conclusion and future work}

Designing mobile money systems to match the capabilities of the people they are meant to serve is essential to growing financial inclusion. Such systems enable illiterate users to develop confidence in the system and scale up financial inclusions. Based on the challenges of illiterate users and their transaction practices, we have proposed a mobile money system that enable them distinguish electronic money notes, and suit their transaction practice like the counting they know. We believe, this work will provoke researchers for more work in this area (either to advance the proposed idea or searching for another one). In our upcoming work, we are planning to consider some ways that enable individuals to be able to make changes, implement and evaluate our design.

\section{$7 \quad$ References}

1. Ahmed I S., Zaber M., and Guha S. 2013. Usage of the Memory of Mobile Phones by Illiterate People. Proceedings of the third ACM Symposium on Computing for Development. New York, USA.

2. Collins D., Morduch J., Rutherford S., and Rutheven O. 2009. Portfolios of the poor. Princeton, NJ: Princeton University press.

3. Duncome R. and Boateng R. 2009. Mobile phones and financial services in developing countries. Reviews of concepts, methods, issues, and evidence and future research directions. Working paper No 37. Centre for development informatics, institute for development policy and management.

4. Grisedale, S., Graves, M and Grünsteidl, A 1997. Designing a graphical user interface for healthcare workers in rural India, Proc. SIGCHI conference on Human factors in computing systems, Atlanta, USA, (1997), 471-478.

5. Jones, M., Buchanan, G., Thimbleby, H., and Marsden, G 2000. User interfaces for mobile web devices mobile workshop position paper. Proc. 9th International World Wide Web Conference. 
6. Kristof D. N. 2010. Cash is so 20th century. I have seen the future in Haiti. http://www.nytimes.com/2010/12/05/opinion/05kristof.html?_r=1 retrieved by March 31, 2011.

7. Lehrer Rachel and West Harry 2014. Literacy a Hidden Hurdle to Financial Inclusion. http://www.cgap.org/blog/literacy-hidden-hurdle-financial-inclusion, retrieved on January 232014

8. Medhi I., Gautama N. S. N., and Toyama K. 2009. A Comparison of Mobile MoneyTransfer UIs for Non-Literate and Semi-Literate Users. CHI 2009, April 4-9, 2009, page 1741-1750, Boston, Massachusetts, USA.

9. Medhi, I., Sagar A., and Toyama K. 2006. Text-Free User Interfaces for Illiterate and Semi-Literate Users. International Conference on Information and Communication Technologies and Development, page 37-50, Berkeley, USA.

10. Parikh, T., Ghosh K.., and Chavan A. 2003. Design Studies for a Financial Management System for Micro-credit Groups in Rural India. ACM Conference on Universal Usability, pp 15-22, Vancouver, Canada.

11. Ruth Branvall 2013. Designing products and services for the illiterates. Inclusive business insights:

http://community.businessfightspoverty.org/profiles/blogs/ruth-branvall-designingproducts-and-services-fory-illiterate retrieved on 23 January 2014.

12. Rutherford S.1999. The Poor and their Money. An essay about financial services for the poor. Institute for development Policy and Management University of Manchester, UK.

13. UNCTAD 2012:

http://unctad.org/en/Pages/newsdetails.aspx?OriginalVersionID=134\&Sitemap_x0020_Ta xonomy=Technology\%20and\%20Logistics, retrieved on 13th December 2013. 